\title{
HISTORIA Y CEGUERA. FRIEDRICH NIETZSCHE EN BAYREUTH
}

\author{
Enrique Gavilán
}

Universidad de Valladolid

Resumen: El artículo intenta poner de relieve cómo en Nietzsche se producen determinados malentendidos sobre la obra de Wagner, que están en la base del conflicto que le opone al músico. Primero, el rechazo de la falsedad wagneriana, sin advertir toda la verdad que encierra esa «mentira». Esa inadvertencia produce una interpretación demasiado superficial de determinadas obras, como Parsifal. En segundo lugar, Nietzsche, especialmente el «filowagneriano", entiende mal la relación que el músico plantea entre drama musical y tragedia griega, y más en general, la relación que el compositor establece con la historia.

Palabras clave: drama musical - tragedia - Parsifal

ABSTRACT: This paper points to certain misunderstandings of Nietzsche regarding Wagner's work which are at the crux of his conflict with the musician. Firstly, the dismissal of Wagnerian untruthfulness, without realizing all the truth contained in this «lie». This lack of realization gave rise to an excessively superficial interpretation of certain works, such as Parsifal. Secondly, Nietzsche, especially in his «philowagnerian» period, misunderstood the relationship the musician proposed between musical drama and Greek tragedy and, more generally, the relationship the composer established with history.

Keywords: musical drama - tragedy - Parsifal

Si se compara el impacto recíproco del músico y el filósofo habría que modificar el título del libro más brillante que el segundo le dedicó al primero, y rebautizarlo, no «caso Wagner», sino más bien «caso Nietzsche». Mientras la figura del músico se convierte ya desde los primeros momentos en una obsesión central del filósofo (por aquel entonces todavía filólogo), por mucho que fuera el aprecio y la admiración que sintiera Wagner por su joven amigo, estuvo siempre muy lejos de la pasión primero y la obsesión después, que dominaron a aquél.

La asimetría se asocia a un conjunto de equívocos en torno al proyecto artístico wagneriano. Un desacuerdo larvado que acabó por transformar en enemigo a quien era al comenzar los años setenta del siglo XIX el más inteligente, sensible y devoto de sus admiradores. Sin embargo, en este caso la acerada lucidez del filósofo se vio enturbiada por la ceguera que provocaba aquello que veneraba. Si se examinan con atención algunos de sus juicios - como antiwagneriano, y sobre todo como filowagneriano-, en medio de sus brillantes epigramas, se descubren incomprensiones sorprendentes. 
La trayectoria artística de Richard Wagner es de una complejidad colosal. Incluso hoy, con una bibliografía oceánica, la posibilidad de un conocimiento exhaustivo de los textos teóricos y de los dramas, cuya representación es frecuente y para los que se dispone además de toda clase de grabaciones, sigue siendo muy difícil comprender los meandros que llevan de Der fliegende Holländer al Ring y de éste a Parsifal, sin mencionar el extraño salto - ien qué dirección?- de Meistersinger. Pero además de un conocimiento más preciso y detallado del conjunto de la obra de Wagner del que pudo tener Nietzsche, a pesar del contacto directo $\mathrm{y}$, durante años, frecuente e intenso, con el propio compositor, disponemos de otra ventaja quizás más importante: perspectiva, todo lo que la historia de la música, del teatro y del pensamiento, la misma historia de Alemania y del mundo, nos han descubierto (o han ido depositando) sobre aquella obra. Sin embargo, sigue resultando confusa y su significado se discute de una forma tan intensa que la polémica no sólo enfrenta a partidarios y detractores, sino que llega a dividir contra sí mismos a algunos de sus comentaristas más lúcidos, como Adorno o Thomas Mann.

Por encima de la manifiesta diferencia generacional y de las menos visibles divergencias teóricas y artísticas, que durante mucho tiempo permanecerán soterradas, Nietzsche y Wagner comparten una insatisfacción común con su tiempo, un disgusto que combina el eco romántico con el desencanto de la etapa posrevolucionaria. En ese disgusto flota también cierta ambigüedad respecto a lo alemán. La filosofía de Schopenhauer, verdadero lazo de unión inicial de esa amistad, traducía la insatisfacción en un plano metafísico, en unos términos que Wagner sabría convertir en dramas fascinantes. Sin embargo, como pondría de manifiesto el desarrollo posterior de la relación, el lazo schopenhaueriano era bastante más sólido que la pasión por la obra dramática que había contribuido a inspirar, a pesar de todas las proclamas nietzscheanas de inquebrantable devoción a la empresa de Bayreuth. En el filósofo se escondía una ambigüedad más viscosa de lo que hubiera podido parecer en los años de intensa amistad. La tensión se alimentaba de una larga serie de malentendidos.

En lo que sigue analizo tres de esos equívocos. En última instancia, se trata de tres aspectos de la misma cuestión, la relación entre la obra de arte y la sociedad en la que surge. Trato de mostrar cómo la hostilidad abierta en torno a Parsifal tiene sus raíces en desacuerdos inexpresados, pero latentes ya en los años anteriores. En su raíz se encuentra el problema del historicismo, la diferencia radical entre la concepción ahistórica de Nietzsche y el hegelianismo teóricamente algo chapucero, pero artísticamente muy eficaz, de Wagner.

En la exposición he preferido invertir el orden cronológico. Parto del momento final, el caso Parsifal, el ejemplo más llamativo de la insensibilidad de Nietzsche a la obra más cercana a sus tesis juveniles. El Bühnenweihfestspiel plantea la disyuntiva entre la denuncia de la falsedad de un arte que necesita disfrazarse (Nietzsche) o la verdad que puede habitar en las obras que mienten (Adorno).

Segundo, el momento de la decepción y la ruptura, el primer festival de Bayreuth, la relación entre el arte y el público. Lo que para Nietzsche era un problema teórico se planteaba al mismo tiempo para Wagner como delicadísima cuestión empresarial, la construcción de un teatro y la puesta en marcha de un festival (el primero de su género). ¿Podía realizarse en el presente una obra de arte concebida para el futuro? ¿Cómo una actitud unzeitgemäß podía adaptarse 
a su tiempo hasta convertir sus creaciones en espectáculo dirigido a un público demasiado concreto, que contaba chistes y comía salchichas en los entreactos?

Tercero, el momento de máxima afinidad, El nacimiento de la tragedia. La ceguera de Nietzsche a la historicidad del arte. La diferencia, raíz de los otros desacuerdos, entre un planteamiento ahistórico en torno a la tragedia, y el hegelianismo contradictorio siempre presente en Wagner, incluso en el más radicalmente schopenhaueriano.

\section{PARSIFAL, LA «FALSEDAD» DE LA OBRA DE ARTE}

De todos los equívocos que se despliegan en esa relación quizás el más expresivo se refiera precisamente a Parsifal. Para Nietzsche representa una maligna concentración de decadencia, beatería y filisteísmo, el núcleo de la perversión wagneriana. En el capítulo de traiciones que, según el filósofo, comete el compositor, la peor, la más escandalosa, la más reveladora de su hipocresía artística era la renuncia vergonzosa a sus propios principios. Como otros tantos rebeldes románticos, el librepensador se arrojaba en brazos de los curas. El inmoral Siegfried se convertía en el piadoso y casto Parsifal; el músico se prosternaba a los pies del crucificado.

Pero si por un lado había allí una lamentable cuestión de principio - la traición que representaba el cambio de pareja de baile: el abate Liszt desplazando a alguien tan hostil al consuelo religioso como Schopenhauer-, por otro, ocurría algo menos evidente, aunque más insidioso; en el Bühnenweihfestspiel culminaba la tendencia histriónica de Wagner, su lado teatral, siempre presente, una perversión que devoraba todo lo que de admirable podía tener su arte. El estudio de la partitura le lleva a Nietzsche a motejar a su autor de Cagliostro de la música, un apelativo que repetirá después con frecuencia.

Sin embargo, ambas acusaciones — catolicismo e hiperteatralidad- son inexactas, y lo que es peor y más revelador, son inexactas por superficiales. Que un analista tan sutil como Nietzsche se muestre tan trivial en un terreno tan importante para él, resulta elocuente. En Parsifal la repulsión que le produce el remedo de las ceremonias católicas, le vuelve ciego a la verdad de un drama muy distinto al que imaginaba, un drama que no es ni tan católico, ni tan patológicamente teatral como creía Nietzsche, y en cierta medida - colmo de las paradojas- en cierto aspecto es muy nietzscheano, naturalmente de un Nietzsche más joven, el que había escrito El nacimiento de la tragedia.

Primero, por debajo de las apariencias escénicas, se trata menos de teatro católico o cristiano que de algo muy distinto. A pesar de todo el despliegue litúrgico, Parsifal es mucho más un drama de inspiración budista que un auto sacramental católico envuelto en armonías tristanescas. El Bühnenweihfestspiel viene a ocupar el lugar del drama oriental que Wagner no llegó a componer, Die Sieger, una obra que se desarrollaba en la antigua India, y cuyos protagonistas eran el propio Buddha y sus discípulos. En Parsifal, bajo el disfraz de la liturgia cristiana, puede descubrirse elementos del hinduismo upanishádico, del hinduismo clásico y, sobre todo, del budismo.

Otro aspecto que agrava la miopía de Nietzsche es la sutileza con la que el compositor se sirve del componente oriental. En ese sentido el recurso al budis- 
mo es todo lo contrario a la tónica orientalista del siglo XIX que tanto debía haber molestado al filósofo. Precisamente la causa probable de que el compositor no escribiera Die Sieger fue su repugnancia al colorido oriental de las muchas óperas de temática india, en la línea de La africana de Meyerbeer. En este aspecto hay que reconocer la superioridad de la discreción del músico en su tratamiento de lo oriental en comparación con las lecturas más o menos disparatadas y descontextualizadas que Nietzsche lleva a cabo de las leyes de Manu, por no hablar de su interpretación del budismo ${ }^{1}$.

Lo teatral le produce al filósofo repugnancia física. El insoportable histrionismo de la creación wagneriana era para él uno de sus peores rasgos y, quizás, el más revelador de su falsedad, del cagliostricismo del compositor. Nietzsche le reprocha la permanente subordinación de la música al drama. Para aguzar la crítica llega a defender óperas de autores menores, precisamente por lo endeble de su contextura argumental, teatralmente un poco idiota, en las que sólo se sostiene (y no mucho) el formalismo de la música.

Para Nietzsche el dominio de lo escénico es una tendencia presente no sólo en el Ring, donde se apoyaba programáticamente en los escritos teóricos de la época de Zúrich (defensa del drama como objetivo artístico supremo), sino también en la fase posterior, en la que Wagner había revisado esas tesis a la luz de la filosofía de Schopenhauer: supremacía de la música, único arte capaz de hacer oír la voz de la voluntad, más allá de las sombras de sombras que se mueven en los escenarios. Así en Tristan und Isolde el drama se había convertido en musikalische Handlung. Sin embargo, el Nietzsche hostil sostenía que por debajo de la proclama tardía en favor de lo sonoro ${ }^{2}$, lo teatral seguía dominando la creación wagneriana. Parsifal, compendio de todas las perversiones, lo ponía de manifiesto con más contundencia que cualquier otro argumento.

Y sin embargo, la sensibilidad de Nietzsche naufraga. La acusación de hiperteatralidad no es certera. El filósofo no advierte la deconstrucción que hay en Parsifal, cómo el compositor consigue cuestionar el dominio del escenario de una forma más enigmática, pero también más eficaz que en sus formulaciones teóricas. Pero la presencia de las ceremonias católicas enfurece a Nietzsche de tal manera que no sabe advertir la sutileza de una construcción artística que las aprovecha para cuestionar el drama, trasladándolo a la música.

El filósofo es incapaz de atravesar la bruma escénica del Bühnenweihfestspiel. De la misma manera que no advierte el drama budista bajo la superficie de los rituales católicos, tampoco acaba de entender la paradoja de la construcción wagneriana. Parsifal es con diferencia la menos teatral de las obras escénicas de su autor, aquella en la que precisamente la música consigue cuestionar, desmentir y desdibujar finalmente los hechos del escenario a través del escenario ${ }^{3}$. Hay

1. Cf. E. Gavilán, «De las ventajas e inconvenientes del resentimiento para el estudio de las religiones: Nietzsche y Weber», en J. B. Llinares (ed.), Nietzsche 100 años después, Valencia: PreTextos, 2002, p. 143.

2. Como Wagner lo define en un escrito breve de la época final, los dramas debían ser simplemente «ersichtlich gewordene Thaten der Musik» (acontecimientos musicales que se hacen visibles), «Über die Benennung 'Musikdrama'», en Gesammelte Schriften und Dichtungen, Leipzig: Elibron Classics, s.d., vol. IX, p. 306.

3. Cf. E. Gavilán, «Prometeo, entre liturgia de la palabra y tragedia de la escucha: Esquilo, Wagner, Nono», en J. V. Bañuls, F. de Martino y C. Morenilla (eds.), El teatro greco-latino y su 
un ascetismo dramático y musical tan intenso que tiende a malinterpretarse. Adorno destaca la renuncia a los recursos musicales que Wagner había sabido emplear con la máxima efectividad en sus dramas, como la capacidad para la transición y el impulso dinámico. Otro tanto ocurre con el lado dramático: «La salvación al final es tan poco creíble como en los cuentos» ${ }^{4}$.

Pero hay algo más que acentúa la ceguera de Nietzsche. Ninguna otra obra de Wagner, incluido Tristan, está tan cerca del planteamiento estético de El nacimiento de la tragedia. En el anteúltimo apartado de esta obra, el filósofo explica cómo se articulan lo dionisíaco y lo apolíneo en la tragedia. Pocos textos más provechosos para orientarse en el laberinto de Monsalvat. Algunos pasajes pueden leerse casi como una glosa sobre las relaciones que se establecen en Parsifal entre el foso y el escenario ${ }^{5}$.

Pero si los prejuicios le ciegan a Nietzsche, al menos no le dejan del todo sordo. Cuando en enero de 1887 escuche en Montecarlo el preludio del Parsifal le revelará a Peter Gast su admiración sin límites ante una música en la que la austeridad se daba la mano con la sutileza más extraordinaria en el uso de los matices ${ }^{6}$.

\section{LA RELACIÓN DE LA OBRA DE ARTE CON SU PRESENTE, LA UNZEITGEMÄSSHEIT}

Nietzsche y Wagner parecen compartir una actitud similar de disgusto y enfrentamiento con su época, lo que el primero formularía como inadaptación a su tiempo, Unzeitgemäßheit ${ }^{7}$. Sin embargo, hay diferencias radicales en el modo en que ambos acabarán interpretándola. En el músico no sólo es compatible con la adaptación que requiere la realización de su proyecto, sino que en cierta medida acaba convirtiéndose en clave secreta de su éxito. Para el filósofo ese éxito desenmascara la falsedad de su antiguo amigo, y por añadidura, la de su obra.

Agosto de 1876, Bayreuth, estreno del Ring, una empresa tan descabellada una década antes que parecía el emblema del sueño utópico, es decir, de lo unzeitgemäß. Nietzsche asiste a la ceremonia en la que el futuro de la obra de arte se convierte en presente muy real, quizás en exceso para quien había compartido un sueño demasiado hermoso para no sentirlo traicionado en aquel ir y venir de sudorosos espectadores engullendo salchichas y cerveza. Como figura más elocuente del uso doméstico de la utopía, el flamante Kaiser, que asiste al

recepción en la tradición occidental, Bari: Levante, 2006, pp. 211-257, e «Iluminación de la ruina, la huella gnóstica en Parsifal», en J. Rabasa y J. Rodríguez Velasco (eds.), Examining the Heretical Thought, Berkeley: Universiy of California Press, 2007.

4. T. W. Adorno, "Zur Partitur des Parsifal», en Moments musicaux, Gesammelte Schriften, Frankfurt a. M.: Suhrkamp, vol. 17, 2003, p. 48.

5. Cf. el apartado 24, KSA I 149 ss., en particular los dos primeros párrafos.

6. KSB VIII 12-13.

7. Lo que se suele traducir como «intempestividad» o «inactualidad». Ciertos matices del término se pierden así inevitablemente. La Unzeitgemäßheit no sólo implica un rechazo de su presente, sino también de la tiranía de lo zeitgemäß, que domina el siglo xix, el «estar al día» (cf. Deutsches Wörterbuch von Jacob und Wilhelm Grimm, München: DTV, 1984, vol. 24, col. 2277). En la bandera de la Unzeitgemäßheit que enarbola Nietzsche hay algo del verso de Evtuchenko: «Quiero ser un poco anticuado para que el tiempo no me borre». 
estreno pero no a las jornadas finales, incapaz de soportar la tetralogía, símbolo mostrenco de su fracaso artístico.

La ceremonia de Bayreuth no sólo culminaba el proyecto estético-político de Wagner, sino también el del Romanticismo. En cierta medida el festival se convertía en paráfrasis del parlamento final de Hans Sachs: "Aunque el sueño de la revolución alemana haya quedado reducido a la decepcionante construcción bismarckiana, siempre nos quedará la hermosa promesa del arte alemán». Cuando en medio de la perfecta oscuridad de la sala ascendiera del foso subterráneo el invisible mi bemol de los contrabajos, en ese sonido culminaría el proceso que había entronizado el arte como sucedáneo de la política, de la filosofía y de la religión. El coro final de Parsifal sería su estadio último. Pero para el Nietzsche que se despegaba del suelo schopenhaueriano, iniciando la fase auroral de su pensamiento, lejos de la oscuridad romántica, el espectáculo de Bayreuth no era sino la confirmación del lado grotesco del viejo sueño, el exceso que lo desenmascaraba.

Más allá de los problemas que derivan de su vulnerabilidad a ciertos gestos, el disgusto de Nietzsche en Bayreuth plantea uno de los problemas más interesantes y a la vez más complejos de la recepción del drama musical, el de su éxito inmediato. ¿Cómo explicar que un arte que rompe consciente y decididamente con los usos de su tiempo, consiga encontrar el asombroso grado de aceptación que recibió entonces? ¿Cómo es posible construir un teatro destinado a representar en exclusiva los dramas de su artífice, dramas concebidos tan de espaldas al presente que se autotitulan del futuro, y hacerlo además en una pequeña ciudad de Alemania alejada de todos los circuitos e inaugurarlo con el estreno de una obra que aún hoy plantea al público exigencias de atención y resistencia completamente inusuales y conseguir atraer a la flor y nata de la sociedad europea?

La clave de ese éxito paradójico radica en su falta de verdad, sostendrá Nietzsche. «El Cagliostro de la Modernidad» había sabido disfrazar su histrionismo envolviéndolo en una pompa vacía. Bajo el falso lema de la anticipación del futuro, el proyecto escondía lo contrario, la búsqueda del éxito a toda costa; para alcanzarlo Wagner se adaptaba al gusto de su mundo, disfrazando su oportunismo de una supuesta Unzeitgemäßheit, tan falsa como los desafortunados decorados del Ring; en última instancia, teatro. El tiempo desenmascarará completamente la superchería que se percibía ya en el festival inaugural. Seis años después, en la farsa pseudorreligiosa del Bühnenweihfestspiel, el compositor adoptará cínicamente el disfraz de penitente, el romántico librepensador se arrodilla frente al dios cristiano para atraer al público hasta la colina verde de Bayreuth. Contra toda la propaganda wagneriana —el mito que rompe el corsé de la historia, la supuesta sublimidad atemporal del drama musical, etc.-, el Festspielhaus ofrecía al público alemán exactamente lo que éste deseaba, y merecía.

Sin duda Nietzsche acierta cuando denuncia lo que hay de falso en el drama musical, pero se equivoca al descalificarlo como mentira. Wagner no era, como Cagliostro, un estafador con olfato para saber qué fantasías debía ofrecer a los incautos, sino un artista auténtico. El músico supo percibir y expresar mejor que nadie algo que flotaba en el ambiente de su época. En cierta medida, en el último cuarto del siglo XIX, que inauguraba la ceremonia de Bayreuth, no había nada más ajustado a su tiempo que una cierta Unzeitgemäßheit. Adorno, distanciándose del juicio de Nietzsche, lo dirá de forma incomparable: «Las grandes obras 
artísticas no pueden mentir. Incluso cuando su contenido es apariencia, contienen como necesaria una verdad de la que las obras artísticas dan testimonio; sólo son inciertas las no logradas» ${ }^{8}$.

Planteada en términos generales, la cuestión del éxito del drama musical resulta mucho menos abordable que si se divide en tantas fracciones como grupos a los que fascina. Lo que seduce a los simbolistas franceses es muy distinto de lo que atrae a los nacionalistas alemanes o lo que inspira a tantos anarquistas catalanes. En otro plano, poco tiene que ver lo que de Parsifal deslumbra a Debussy con lo que les interesa a Mahler o a Schönberg. Sin embargo, abordar la cuestión de esa forma desbordaría completamente este marco ${ }^{9}$. Es necesario limitarse a una respuesta más general, por imprecisa que resulte.

Hay una fibra común ${ }^{10}$ en la muy diferente atracción que ejerce el drama musical sobre el imaginario de personas y grupos tan distintos como los que en el pasado integraron la heterogénea nómina wagneriana. Se trata menos de un elemento concreto que de determinadas combinaciones. Éstas convierten la obra de Wagner en una especie de piedra filosofal capaz de despertar tanto la admiración que deriva de un largo proceso de asimilación, como la fascinación más inmediata. Esas asociaciones resultan tan paradójicas que a veces provocan reacciones contradictorias en una misma persona, como en Nietzsche, pero también en los dos autores que junto con él encabezarían la lista de los intérpretes más interesantes del drama musical, Adorno y Thomas Mann. En Doktor Faustus, Adrian Leverkühn encarna esa escisión. La simboliza precisamente su reacción al preludio del acto III de Meistersinger. Adrian se siente conmovido hasta las lágrimas, pero al mismo tiempo no puede reprimir las carcajadas, pues percibe el elemento mecánico que se escucha en las notas graves. En la novela esa contradicción se convierte en símbolo de la peligrosa dualidad de la cultura alemana, el elemento oscuro que en «Alemania y los alemanes» Mann identificará con la música ${ }^{11}$.

Wagner, apoyado en un instinto artístico único, no respeta fronteras ideológicas, teóricas o estéticas. Las singulares combinaciones que se dan en su obra ejercieron una atracción tan fuerte sobre su época, de hecho la han seguido ejerciendo hasta hoy, porque esa fascinante mezcla de materiales contradictorios le permitía extender su influencia en casi todas las direcciones. Ahora bien, la heterogeneidad de una obra no es garantía de su éxito, ni a corto ni a largo plazo. Hacen falta otras condiciones, entre ellas la coherencia del resultado, como en el Ring, donde consigue asociar a Hegel y Schopenhauer sin que en ningún momento el resultado parezca un híbrido monstruoso; todo lo contrario ${ }^{12}$.

8. T. W. Adorno, Ästhetische Theorie, Frankfurt a. M.: Suhrkamp, 1992, p. 196.

9. A este respecto, cf. D. C. Large y W. Weber (eds.), Wagnerism in European Culture and Politics, Ithaca/London: Cornell University Press, 1984.

10. Dejando aparte el valor artístico de la obra de Wagner, pero ésa no es la cuestión; el problema es lo temprano del éxito de una obra que por su novedad y su complejidad debería haber planteado enormes dificultades de asimilación.

11. El pasaje de Doktor Faustus se encuentra en el capítulo XV, cf. T. Mann, Gesammelte Werke in Dreizehn Bände, Frankfurt a. M.: Fischer, 1990, vol. VI, pp. 178 ss. El pasaje sobre la música en «Deutschland und die Deutschen», op. cit., vol. XI, pp. 1131-1132. En este texto despliega las ideas de la novela en forma de ensayo. Poco después reaparecerían como eje de otro texto, cuyo tema, de forma nada casual, iba a ser precisamente Nietzsche: «Nietzsches Philosophie im Lichte unserer Erfahrung», op. cit., vol. IX, pp. 675-712.

12. En la edición de sus obras completas Wagner dejó itres! finales distintos para Götterdäm- 
Pero tampoco basta con la coherencia de materiales tan heterogéneos. El drama musical producía y produce además una impresión de verdad tan desconcertante y efectiva como la que despierta, por ejemplo, la figura de Beckmesser, el tradicionalista que canta la música más innovadora de Meistersinger, el drama en el que el compositor reorienta su proyecto estético, y lo hace a través de las polaridades múltiples que lo atraviesan.

Entre las ambigüedades que surcan el drama musical hay una clave, que Nietzsche no sabe comprender. Se trata de un movimiento contradictorio con relación al pasado, cierta mezcla de nostalgia romántica y promesa escatológi$\mathrm{ca}^{13}$, el doble gesto aparentemente imposible de transfiguración y rechazo de la historia. Ese gesto ambiguo que recorre el drama musical desconcertó lo bastante al filósofo como para que cerrara su último texto favorable al compositor, la cuarta Consideración intempestiva, con uno de sus diagnósticos menos certeros sobre el significado del drama wagneriano y su futuro ${ }^{14}$.

Para explicar el uso paradójico de la historia en Wagner, la necesidad de disfrazarse con las ropas del pasado para hablar del futuro, Adorno desarrolló el concepto de fantasmagoría ${ }^{15}$, del que tan buen uso haría su amigo Benjamin. La fantasmagoría de la historia se convierte en el disfraz de una sociedad que ha iniciado la vertiginosa marcha hacia el futuro al tiempo que rechaza la Modernidad, otra cara del Sonderweg alemán, la vía prusiana al capitalismo. El disfraz se convierte así en la única imagen posible de un futuro tan temido como inevitable, provocado en parte por los mismos que aborrecen sus efectos. El fracaso de la revolución y la realización parcial de sus objetivos bajo la hegemonía de los Junker priva a la política de la fascinación que pudo haber ejercido a mediados de siglo. El arte viene a ocupar ese lugar. Con Wagner se produce un avance decisivo en el proceso: la estética sustituye a la política. El movimiento desembocará en la estetización de la política en el fascismo, que tan certeramente diagnosticó Walter Benjamin ${ }^{16}$, cuya culminación inevitable debía ser la guerra.

Nietzsche sólo percibía lo que había de falso en la fantasmagoría de Parsifal, sin advertir su necesidad y su verdad. En el fondo de esa insensibilidad está la incomprensión de lo que el drama musical revelaba sobre aquella sociedad que participaba alborozada en la ceremonia de Bayreuth. Por debajo está siempre el problema del historicismo, frente al cual, y en relación con Wagner, Nietzsche había puesto en evidencia una ceguera crónica, la que se manifiesta de forma espectacular en el final ya citado de la cuarta Intempestiva. Esa ceguera estaba presente casi desde sus inicios wagnerianos; había aparecido ya en El nacimiento de la tragedia. Allí es incapaz de advertir la historicidad del drama musical, que

merung: uno feuerbachiano, otro budista, y un tercero, el que aparece en la partitura, puramente orquestal, con toda la ambigüedad que implicaba.

13. Cf. E. Gavilán, «Mito e historia en Wagner. El papel del teatro griego en la revuelta contra el historicismo", en El perfil de les ombres, Bari: Levante, 2002, pp. 205-224.

14. «No puede ser para nosotros, como desearíamos, el visionario de un futuro, sino el intérprete y transfigurador de un pasado» (KSA I 510).

15. Cf. T. W. Adorno, Versuch über Wagner. Die musikalischen Monographien, Frankfurt a. M.: Suhrkamp, 1952, pp. 82 ss.

16. Cf. W. Benjamin, Das Kunstwerk im Zeitalter seiner technischen Reproduzierbarkeit, en Gesammelte Schriften, vol. I/2, Frankfurt a. M.: Suhrkamp, 1991, pp. 506 ss. 
se convierte en manifestación de las mismas fuerzas intemporales que animaron la tragedia griega.

\section{EL PROBLEMA DEL HISTORICISMO, LA CEGUERA ANTE LA HISTORIA: TRAGEDIA GRIEGA Y DRAMA MUSICAL}

Tras el deslumbramiento del idilio de Tribschen se esconden malentendidos que durante mucho tiempo permanecerán reprimidos o inexpresados, disonancias residuales, pálidas frente al brillo de una cadencia lograda. Cuando finalmente Nietzsche rompa con Bayreuth no será sólo como consecuencia de su evolución intelectual, ni de las dificultades de una relación personal llena de puntos de fricción, sino que en la ruptura se manifiestan también aquellos malentendidos. Entre las disonancias semiocultas está el desacuerdo obvio, y sin embargo silenciado, del joven Nietzsche con su entonces adorado Wagner en un aspecto crucial de su proyecto artístico, el papel de la historia, la relación del presente con el pasado (el teatro griego) y el futuro, y más allá, la cuestión del tipo de vinculación de cualquier creación artística con el contexto en el que surge.

La relación entre el drama musical y la tragedia griega representaba un problema clave tanto para Wagner como para Nietzsche. El músico lo había tratado ampliamente en sus obras teóricas, ante todo en Ópera y drama. Por otra parte, la actualidad de la tragedia, su renacimiento en el drama musical, constituía el tema del primer gran texto de Nietzsche. A través del problema teórico el pensador se enfrentaba a otra cuestión vital para él, el sentido de su profesión ${ }^{17}$.

Lo extraordinario es que a pesar de la importancia de la cuestión y del armonioso acuerdo que parecía existir entre ambos, uno y otro sostenían tesis muy diferentes. Sin embargo, de forma casi milagrosa, la divergencia no llega a manifestarse como oposición abierta. Si se atiende solamente a sus manifestaciones habría que concluir que ambos compartían la misma idea, y no era así. Al contrario, por debajo de esa divergencia escondida se dibujaba una oposición profunda que acabaría estallando con estrépito años más tarde.

Una simple pregunta habría permitido que el desacuerdo aflorara. Si se les hubiese planteado a ambos cuál era la relación entre la obra de Esquilo y la de Wagner, por ejemplo, si existían diferencias esenciales entre Prometeo encadenado y Tristan und Isolde, quizás uno y otro se habrían sorprendido al descubrir el abismo que separaba sus respuestas.

Nietzsche explicaba Prometeo, o cualquier otra tragedia de Esquilo, como manifestación de lo dionisíaco (Wille-música-coro) en equilibrada combinación con el elemento apolíneo que permitía su representación (Vorstellung-expresión escénica-diálogo, etc.). Siglos después, en la obra de Wagner reaparecían bajo otra encarnadura los mismos elementos que habían definido la tragedia; el drama musical sería simplemente su renacimiento (Wiedergeburt). En Wagner volvía a manifestarse la fuerza de lo sonoro que permitía el resurgimiento del

17. Más bien su falta. En el mismo momento en que escribe los trabajos que conducirán a $E l$ nacimiento de la tragedia, Nietzsche trata infructuosamente de que la Universidad de Basilea acepte su paso a una cátedra de filosofía entonces vacante, abandonando la de filología. Las objeciones contra lo que significaba su profesión constituirán la materia prima de las Consideraciones intempestivas. 
mismo elemento dionisíaco (Wille-música-orquesta) articulado con lo apolíneo (Vorstellung-texto-gesto). En ese sentido nada esencial diferenciaría Prometeo de Tristan, salvo quizás - como probablemente hubiese destacado Hegel con malévola y demoledora ironía- que su autor, a diferencia del griego, había leído a Schopenhauer, lo que le permitía articular de forma explícita aquella dualidad como oposición - dramática, musical y metafísica- de Noche y Día ${ }^{18}$.

Pero si para Nietzsche Esquilo representa lo igual, para Wagner representa justamente lo diferente; ahí radicaba su valor. Por grande que fuese la admiración del músico hacia el dramaturgo, en ningún momento llega a concebir sus obras como renacimiento, restauración o resurrección de la tragedia ateniense. En el Wagner más schopenhaueriano se conserva un residuo hegeliano que le impide aceptar la ahistoricidad que implican las tesis de El nacimiento de la tragedia. Precisamente la conciencia de esa diferencia resultaba crucial para el músico. El valor de Esquilo radicaba en que representaba algo esencialmente distinto del teatro del siglo xix. Se convertía así en punto de apoyo para pensar la posibilidad de otro teatro. De la misma forma que a la sociedad griega le correspondía una forma artística tan singular como la tragedia de Esquilo, a una sociedad futura le correspondería otra muy distinta de la ceremonia trivial a la que la sociedad burguesa había reducido el teatro. El drama musical no se plantea ya como restauración o renacimiento sino como obra de arte que anticipa un futuro.

Cuando Nietzsche escribe El nacimiento de la tragedia, el drama musical que tiene presente es casi exclusivamente Tristan. Hay una desatención completa, no ya a sus óperas románticas, sino al Wagner que escribe por aquel entonces las últimas páginas de la tetralogía, su gran proyecto, una obra que tiene por lo menos tanto Feuerbach (y Hegel) como Schopenhauer. Algo similar ocurre respecto a las obras teóricas. El único Wagner que cuenta para Nietzsche es el archischopenhaueriano que ha escrito Beethoven. Hay un vacío tan inmenso en el lugar que debía ocupar Ópera y drama, que se ha de concluir o bien que el filósofo había eludido su lectura, o bien que había conseguido olvidarla concienzudamente. Y sin embargo, por debajo de todos los giros estéticos, políticos o religiosos, en Wagner hay una continuidad sorprendente en sus temas, la que lleva a descubrir en el Holandés buena parte de los elementos que aparecerán cuarenta años después en Parsifal. Aún más elocuente, a mediados de los años cuarenta, es decir, bastante antes de la revolución y la ruptura estética de mediados de siglo, el compositor había decidido ya la materia de casi todos sus dramas posteriores (Lohengrin, el Ring, Meistersinger y Parsifal).

Podría parecer llamativo que Wagner y su círculo no manifestasen ninguna reserva frente a las tesis abistóricas de El nacimiento de la tragedia. Por el contrario, entre los wagnerianos la obra se recibió con un entusiasmo sin matices. Ese desinterés por la disonante interpretación del drama musical como Wiedergeburt de la tragedia griega se explica fácilmente cuando se tiene en cuenta, por una parte, la deriva de Wagner hacia Schopenhauer, en cuya filosofía la historia se convertía en una especie de pariente estúpida de saberes mucho más interesan-

18. Ahora bien, si —como sostenía Nietzsche- el drama musical era un nuevo nacimiento de la tragedia, Parsifal sería su reencarnación más perfecta. Quizás — habría apuntado Hegel, de nuevo irónico- porque en este caso el autor había leído antes El nacimiento de la tragedia, lo que debió de facilitarle el trabajo. 
tes, lo que autorizaba a no tener demasiados miramientos con ese tipo de precisiones. Por otra parte, el músico no era precisamente Lenin, ni con sus textos o los de sus simpatizantes estaba tratando de definir los estatutos o la estrategia de un partido revolucionario. Wagner es un aficionado carente de rigor o de escrúpulos teóricos, dispuesto a aprovechar todo lo que le sirva para promocionar su proyecto, en una actitud que tiene mucho más de bricoleur que de arquitecto. Cuando uno compara hoy la brillantez de El nacimiento de la tragedia con los pesados textos wagnerianos puede entender que cualquier desacuerdo de detalle desapareciera del horizonte. Si el compositor tenía necesidad de sentirse intelectualmente superior al filósofo le bastaba con pedirle que interpretara sus partituras al piano.

Por otra parte, la coincidencia schopenhaueriana debió parecer un suelo lo bastante sólido como para que sostuviera sin grandes conmociones lo que en aquel tiempo podían parecer simples desacuerdos de detalle, relacionados además con un terreno donde los conocimientos del filólogo eran muy superiores. Finalmente hay que tener en cuenta que a Wagner y su círculo les interesaba sobre todo la autoridad académica que representaba la voz de Nietzsche. Que a principios de los años setenta un catedrático de filología clásica produjera una obra como aquella en la que, desde la respetada legitimidad de la ciencia, defendía el drama musical como reencarnación y continuación de la tragedia de Esquilo, y lo presentara en un marco conceptual schopenhaueriano, con una originalidad y una prosa tan deslumbrantes, produjo el comprensible entusiasmo sin reservas en Wagner ${ }^{19}$.

En todo caso tras el desacuerdo «menor» sobre si las obras de Wagner eran o no un «renacimiento» del drama griego, se dibujaba un tema mayor, el gran debate del último cuarto del siglo XIX, la crisis del historicismo, un asunto decisivo para Nietzsche, sobre el que se centrará otro texto capital, la segunda Intempestiva: el significado del pasado en el presente, el modo de conocerlo, de presentarlo o representarlo, la relevancia de la historia, su contraposición al arte, las relaciones de ambas con la vida, etcétera.

Desde el primer momento hay en Nietzsche una actitud muy diferente hacia el historicismo, de la que late en los dramas y las obras doctrinales de su amigo, divergencia que, como la relativa a la relación del drama musical con la tragedia griega, tampoco llega a expresarse. En Wagner, incluso en su etapa decididamente schopenhaueriana, hay mucho más Hegel del que resultaba compatible con la posición de Nietzsche, en particular y de forma paradójica, con el joven que escribe su obra más wagneriana, El nacimiento de la tragedia ${ }^{20}$. Pero si en su momento - la miopía que el amor produce- las diferencias en este punto no son reconocidas por ninguno de los dos, resultan aún más interesantes porque tampoco son aprovechadas por el Nietzsche hostil en su ofensiva anti-wagneriana.

19. La paradoja: Nietzsche quedará desahuciado como autoridad filológica —aquello que más le interesaba a Wagner- por poner la filología al servicio del drama muscial.

20. Ventajas del amateurismo del bricoleur que es Wagner frente al rigor teórico de su amigo. El músico tiene auténtico desparpajo para la incoherencia: puede firmar Beethoven sin desahuciar Ópera y drama. Pero toda la incompetencia teórica de Wagner se convierte en habilidad para servirse artísticamente de sus indigestos tratados doctrinales. Después de escribir Beethoven tenía que terminar todavía el Ring, cuyo soporte teórico eran los escritos de Zúrich. En ese caso la coherencia teórica hubiera implicado la impotencia artística. 
En Nietzsche hay una rebelión contra el hegelianismo que impregna su siglo. En última instancia el lema que preside sus obras de los primeros años setenta es la Unzeitgemäßheit. Traduce la actitud de quien quiere pensar al margen de su tiempo, de quien intenta saltar por encima de su sombra. Wagner es demasiado sensatamente hegeliano para plantearse tales empresas. En realidad, su vacuna es la incoherencia teórica. Cuando se plantee escribir La obra de arte del futuro, en cierta medida, una obra contra la historia, el historicismo reaparecerá por todos los poros ${ }^{21}$. Meistersinger, una obra decididamente schopenhaueriana, en la que hay pasajes, como el monólogo del Wahn, que contienen citas literales de El mundo como voluntad y como representación es, sin embargo, una vuelta a la ópera histórica, incluso a una ópera exageradamente histórica, en la que hasta la música imita corales luteranos o bars, donde reaparecen coros, quintetos, etc $^{22}$. La ironía permanente de sus obras le permite realizar el gesto del que salta sobre su sombra, mientras sugiere al mismo tiempo la imposibilidad de tal salto. Joachim Fest afirmaba que el drama musical era la primera manifestación del posmodernismo ${ }^{23}$.

\section{LA DECEPCIÓN DE SACHS}

Cuando Nietzsche volvió a casa de Malwida tras la última de las jornadas del primer ciclo del Ring, la amargura era más fuerte que el agotamiento. El mal humor parecía invencible. La vulgaridad de los burgueses franconianos le perseguía. En realidad se sentía molesto consigo mismo. No había conseguido encontrar el momento para la hermosa tirada sobre el arte alemán y su necesaria Unzeitgemäßheit. Walther estaba mucho más pendiente de los invitados importantes que de aquel singular filólogo capaz de descubrir en su música el poder del dios que uncía a tigre y pantera, de reconocer la tragedia en el drama musical. Quizás todo habría resultado de otra forma si el concurso de canto no se hubiese decidido de antemano y de él dependiera la mano de Eva, pero Walther la desposó seis años antes en Lucerna. En el fondo Sachs lamentaba profundamente su renuncia, por sensata que hubiese parecido en aquel momento sublime del acto III, pero las armonías de Tristan lo habían desarmado. Cuando Dioniso llegase a Naxos sólo encontraría una isla desierta.

21. Cf. E. Gavilán, «El papel del teatro griego...», cit.

22. Cf. E. Gavilán, «De la supervivencia de Eva y la imposibilidad de la revolución: Los maestros cantores de Nürnberg», en F. de Martino y C. Morenilla (eds.), El caliu de l'oikos, Bari: Levante, 2004, pp. 247-274.

23. J. Fest, «Richard Wagner - Das Werk neben dem Werk. Zur ausstehenden Wirkungsgeschichte eines Großideologen», en S. Friedländer y J. Rüsen (eds.), Richard Wagner im Dritten Reich, München: Beck, 2000, p. 28. 